The apparent 'distribution space' was calculated as :

Metabolic clearance rate (ml/min per $\mathrm{kg}$ body wt.)

$$
K\left(\min ^{-1}\right)
$$

where $K=0.693 / t_{1 / 2}$. These values were measured in 12 cases of liver disease and 12 cases of thyroid disease, and these were compared with values obtained in eight normal subjects.

The mean $t_{1 / 2}$ was prolonged in the groups with liver disease (31.8min) and myxoedema (24 min) when compared with the normal group (18.75 min); $P$ values were $<0.001$ and $<0.025$ respectively.

The difference in mean metabolic clearance rate was less marked between the groups (2.13, 2.55 and $3.13 \mathrm{ml} / \mathrm{min}$ per $\mathrm{kg}$ body wt.; $P$ values $<0.02$ and $<0.01>0.05$ respectively).

There was no significant correlation between $t_{1 / 2}$ and metabolic clearance rate. This discrepancy between $t_{1 / 2}$ and metabolic clearance rate was due to variation in 'distribution space'. In the normal group the mean 'distribution space' was 80 (range 70-95) $\mathrm{ml} / \mathrm{kg}$ body wt., and in the group with liver disease it was 106 (range 40-190) $\mathrm{ml} / \mathrm{kg}$ body wt. In the liver patients there was a very close correlation between metabolic clearance rate and 'distribution space' $(r=0.9430 ; P<0.001)$. A similar correlation existed in the other groups.

Thus $t_{1 / 2}$ does not give a meaningful estimate of the metabolism of human growth hormone. The apparent 'distribution space', which until now has been largely overlooked, is clearly of major importance in determining the rate of metabolism of growth hormone in man. The implications of these observations will be discussed.

Srivastava, M. C., Tompkins, C. V., Sönksen, P. H. \& Nabarro, J. D. N. (1970). Diabetologia, 6, 648.

\section{The Preparation and Characterization of} Labelled Rat Growth Hormone

By R. V. Davies and M. Waulis. (School of Biological Sciences, University of Sussex, Falmer, Brighton BN1 9QH, U.K.)

If a protein can be made in which every residue is labelled with a radioactive isotope, techniques for determination of the amino acid sequence could be made more sensitive, since peptides, amino acids and their derivatives could be detected by virtue of their radioactivity. We have prepared internally ${ }^{14} \mathrm{C}$-labelled rat growth hormone, by biosynthesis in vitro, that should be suitable for such sequence studies.

Male rat anterior pituitaries were incubated for $20 \mathrm{~h}$ in a simple bicarbonate-buffered medium (Gey \& Gey, 1936) with the addition of $1 \mathrm{mg}$ of glucose,
$1 \mathrm{mg}$ of bovine serum albumin, $1 \mu \mathrm{g}$ of penicillin $\mathrm{V}$, and $50 \mu \mathrm{g}$ of streptomycin $/ \mathrm{ml}$. ${ }^{14} \mathrm{C}$-labelled forms of all 20 amino acids normally found in proteins were added at a concentration of about $5 \mu \mathrm{Ci}$ of each amino acid per five anterior pituitaries. Growth hormone with a specific radioactivity of about $10 \mu \mathrm{Ci} / \mu \mathrm{mol}$ was prepared by preparative polyacrylamide-gel electrophoresis of salt extracts of the anterior pituitaries.

Amino acid analyses of acid hydrolysates, and of Pronase and leucine aminopeptidase digests (to determine asparagine, glutamine and tryptophan), were carried out by paper electrophoresis and chromatography, followed by scintillation counting of the amino acid spots. Each type of residue contained label. The relative specific radioactivity of each type of residue was determined, from the published composition of rat growth hormone (Ellis, Grindeland, Nuenke \& Callahan, 1968) with correction, where necessary, for ninhydrin decarboxylation. Peptide 'maps' of tryptic digests of performic acid-oxidized ${ }^{14} \mathrm{C}$-labelled growth hormone were prepared by radioautography; they show a marked similarity to 'maps' of tryptic peptides of oxidized ox (Wallis, 1966) and sheep (Davies, 1971) growth hormones. Amino acid compositions of some of the tryptic peptides have been determined, again by detecting and estimating amino acids by virtue of their radioactivity.

We thank the Medical Research Council for a research grant (to M. W.) and a Postgraduate Scholarship (to R. V. D.)

Davies, R. V. (1971). D.Phil. Thesis: University of Sussex. Ellis, S., Grindeland, R. E., Nuenke, J. M. \& Callahan, P. X. (1968). Ann. N.Y.Acad. Sci. 148, 328.

Gey, G. O. \& Gey, M. K. (1936). Am. J. Cancer, 27, 45. Wallis, M. (1966). Biochim. biophys. Acta, 115, 423.

Breakdown of Indo1-3-ylacetic Acid by Corynebacterium fascians (Tilford) Dowson

By D. R. Kemp and T. I. Steenson. (Department of Biochemistry, Chelsea College of Science and Technology, Manresa Road, London S.W.3, U.K.)

Changes in the synthetic and degradative metabolism of indol-3-ylacetic acid may account for the characteristic symptoms that occur in plants infected with either Corynebacterium fascians (Lacey, 1936a,b, 1942, 1948, 1955, 1961) or Agrobacterium tumefaciens (Brown \& Gardner, 1936).

Indol-3-ylacetaldehyde and tryptophol are formed during the synthesis of indol-3-ylacetic acid from L-tryptophan by the radicles of Lens culinaris (Hofinger \& Gaspar, 1969). Indol-3-ylacetaldehyde 
is also produced by cell-free extracts of Pseudomonas solanaceacum (Phelps \& Sequeira, 1967a,b) and by $A$. tumefaciens, which in addition produces indol-3-yl-lactic acid and tryptophol (Kaper \& Veldstra, 1958). Plant epiphytic bacteria produce indol-3-ylacetic acid, indol-3-ylpyruvic acid, indol-3-ylcarboxaldehyde and indol-3-ylcarboxylic acid from tryptophan (Wichner \& Libbert, 1968).

3-Methyleneoxindole formation during enzymic oxidation of indol-3-ylacetic acid has been reported by Hinman \& Lang (1965), and during studies on the metabolism of indol-3-ylacetic acid by horseradish peroxidase Meudt (1965) isolated four indole derivatives one of which showed considerably greater auxin-like activity than that of indol-3ylacetic acid. Indole and anthranilic acid were identified among products of indol-3-ylacetic acid metabolism by C. fascians (Dean, 1961).

The following experiments on the metabolism of indol-3-ylacetic acid by $C$. fascians suggest that tryptophol may be an important product formed by a reversal of the indol-3-ylacetic acid-synthetic pathway.

The organism was grown in nutrient salt medium containing indol-3-ylacetic acid $(50 \mu \mathrm{g} / \mathrm{ml})$. Changes in indol-3-ylacetic acid concentration were monitored by using the Salkowski reagent and reading the colours at 430nm (Marumo, Abe \& Hattori, 1968). Breakdown products were recognized by paper chromatography.

Breakdown of indol-3-ylacetic acid by induced cells (previously grown on indol-3-ylacetic acid) in unbuffered medium ( $\mathrm{pH}$ 6.9) lacking either a nitrogen or a carbon source was rapid $(0.20 \mu \mathrm{mol}$ of indol3-ylacetic acid/min per $\mathrm{mg}$ of protein). In similar experiments with buffered media (pH6.0 and 6.6) no indol-3-ylacetic acid breakdown products could be detected chromatographically.

In an unbuffered complete nutrient medium (pH 6.9) indol-3-ylacetic acid was metabolized less rapidly, and a number of breakdown products including indol-3-ylacetaldehyde, tryptophol, indole and anthranilic acid were detected. Low $\mathrm{pH}$ values between 5.0 and 6.0 favoured the production of tryptophol.

These results suggest that $C$. fascians may metabolize indol-3-ylacetic acid via a reversal of the normally accepted pathway for its synthesis, the major end products depending on the $\mathrm{pH}$ of the reaction medium, low $\mathrm{pH}$ values favouring tryptophol production.

Brown, N. \& Gardner, F. E. (1936). Phytopathology, 26, 708.

Dean, C. (1961). D.I.C. Dissertation: University of London.

Hinman, R. L. \& Lang, J. (1965). Biochemistry, Easton, 4, 144.
Hofinger, M. \& Gaspar, T. (1969). Bull. Soc. r. Bot. Belg. $102,197$.

Kaper, J. M. \& Veldstra, H. (1958). Biochim. biophys. Acta, 30, 401.

Lacey, M. S. (1936a). Ann. appl. Biol. 23, 302.

Lacey, M. S. (1936b). Ann. appl. Biol. 23, 743.

Lacey, M. S. (1942). Ann. appl. Biol. 29, 11.

Lacey, M. S. (1948). Ann. appl. Biol. 35, 572.

Lacey, M. S. (1955). Trans. Br. mycol. Soc. 38, part 1.

Lacey, M. S. (1961). Ann. appl. Biol. 49, 634.

Marumo, S., Abe, H. \& Hattori, H. (1968). Agric. biol. Chem., Tokyo, 32, 117.

Meudt, W. J. (1965). Pl. Physiol., Lancaster, 40 (Suppl.), lxxi.

Phelps, R. H. \& Sequeira, L. (1967a). Pl. Physiol., Lancaster, 42, 1161.

Phelps, R. H. \& Sequeira, L. (1967b). Phytopathology, 57, 1182.

Wichner, S. \& Libbert, E. (1968). Physiologia Pl. 21, 227.

Metabolism of $\mathrm{C}_{1}$ and $\mathrm{C}_{2}$ Compounds by Pseudomonas AM 1: a Glycerate Kinase Mutant and a Mutant Defective in Glyoxylate Formation from $G_{1}$ Compounds

By C. Anthony, P. M. Dunstan and W. T. DrabBle. (Department of Physiology and Biochemistry, University of Southampton, Southampton SO9 5NH, U.K.)

Glyoxylate is an intermediate in the serine pathway for the assimilation of $\mathrm{C}_{1}$ compounds and oxalate by Pseudomonas AMI (Blackmore \& Quayle, 1970; Harder \& Quayle, 1971).

There is considerable evidence that one of the enzymes required for glyoxylate formation from $\mathrm{C}_{1}$ compounds is also involved in the pathway for assimilation of ethanol in Pseudomonas AM 1 (Anthony, Dunstan \& Drabble, 1971). It might be predicted that this common reaction is not involved in a direct condensation of $C_{1}$ units to give a $C_{2}$ compound, nor in the formation of glycolytic intermediates from serine. Experiments with the two mutants described here confirm this prediction, and support the suggestion (Anthony et al. 1971) that enzymes are present in Pseudomonas AM 1 that convert acetate into glycollate and glyoxylate.

Mutant PCT-64 does not grow on any $\mathrm{C}_{1}$ compound (even in the presence of glycollate or glyoxylate), nor on oxalate, but grows well on ethanol or succinate. No glycerate kinase could be detected in this mutant, but hydroxypyruvate reductase, serine-glyoxylate aminotransferase and enzymes for the oxidation of $\mathrm{C}_{1}$ compounds are present. This result confirms that glycerate kinase is not essential for growth on ethanol, and that it is an essential enzyme of the serine pathway for the assimilation 